\title{
Premature spinal fusion after insertion of magnetically controlled growing rods for treatment of early-onset scoliosis: illustrative case
}

\author{
Anna H. Green, MD, Andrzej Brzezinski, MD, Terrence Ishmael, MD, Stephen Adolfsen, MD, and J. Andrew Bowe, MD \\ Department of Orthopedic Surgery, Robert Wood Johnson University Hospital, New Brunswick, New Jersey
}

BACKGROUND Magnetically controlled growing rod (MCGR) systems have gained attention for their use in the treatment of early-onset scoliosis. Although traditional growing rods require frequent operations to lengthen the construct, MCGR allows for fewer open procedures and more frequent distractions by externally controlling rod elongation. Despite its appealing advantages, MCGR is not without limitations.

OBSERVATIONS The authors describe a case of premature spinal autofusion before growing rod removal and termination of rod distraction.

LESSONS This case highlights the limitations of MCGR systems, including length of use, body habitus restrictions, and risk of autofusion.

https://thejns.org/doi/abs/10.3171/CASE21446

KEYWORDS growing rods; scoliosis; autofusion; early onset

In recent years, growth-friendly surgical techniques have gained popularity for the treatment of early-onset scoliosis for which nonoperative treatment has failed. Although spinal fusion allows significant deformity correction, early fusion may result in severe restrictive pulmonary disease, ${ }^{1}$ the crankshaft phenomenon, and shortened truncal height. ${ }^{2}$ The insertion of subcutaneous or intramuscular rods that can be progressively distracted allows growth of the spine and lungs while also controlling the curvature until the patient reaches skeletal maturity, at which point he or she can be transitioned to a definitive fusion. ${ }^{3}$ Traditional growing rods (TGRs) require return to the operating room at roughly 6-month intervals in order to lengthen the construct. Magnetically controlled growing rod (MCGR) systems use a system of magnets to lengthen the rods, and they are typically used in an outpatient setting. This involves placing an external remote over the actuators, which distracts the rods to a predetermined length. Although MCGRs offer the advantage of a significantly decreased number of operations, they are not without limitations and complications. Failure to distract eliminates the benefit of using these systems and has been most frequently reported as secondary to anchor pullout (11.8\%), implant failure $(11.7 \%)$, and rod breakage $(10.6 \%) .{ }^{4}$ Herein, we report a case of failure of elongation of the rods due to premature fusion of the spine.

\section{Illustrative Case}

The patient was an 11-year-old boy with a history of Prader-Willi syndrome. He initially presented to our institution at the age of 3 years for evaluation of his scoliosis. At that time, he was diagnosed with a left thoracic early-onset scoliosis apparent on magnetic resonance imaging (MRI) studies and chest radiographs. MRI evaluation of the spine showed no neurological or vertebral anomalies. Over the next 39 months, he underwent serial Risser body casting followed by functional bracing. This was unsuccessful at halting progression of his deformity, because it reached over $75^{\circ}$ in the sagittal plane and $86^{\circ}$ in the coronal plane (Fig. $1 A$ and $B$ ). At the age of 7 , he was placed in halo gravity traction for 5 weeks to improve his deformity before growing rod placement. His kyphosis improved to $60^{\circ}$ and his scoliosis to $36^{\circ}$ (Fig. 1C and D).

Subsequently, still at age $7(116.8 \mathrm{~cm}$ height, $28.9 \mathrm{~kg}$ weight with body mass index [BMl] $21.2 \mathrm{~kg} / \mathrm{m}^{2}$, 90th percentile by weight, 15 th percentile by stature, according to the Centers for Disease Control and Prevention

ABBREVIATIONS BMI = body mass index; MAGEC = MAGnetic Expansion Control system; $M C G R=$ magnetically controlled growing rod; MRI = magnetic resonance imaging; TGR = traditional growing rod.

INCLUDE WHEN CITING Published October 25, 2021; DOI: 10.3171/CASE21446.

SUBMITTED August 7, 2021. ACCEPTED September 10, 2021.

(c) 2021 The authors, CC BY-NC-ND 4.0 (http://creativecommons.org/licenses/by-nc-nd/4.0/). 

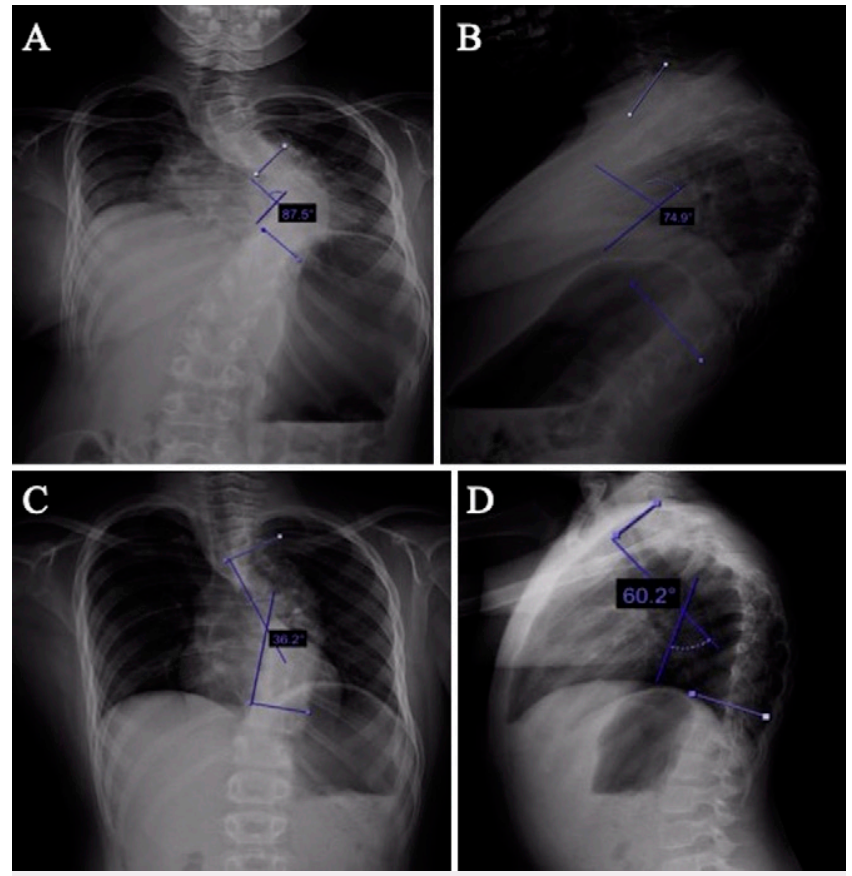

FIG. 1. Preoperative spine radiographs at the age of 7 before ( $A$ and B) and after (C and D) halo gravity traction.

growth chart ${ }^{5}$ ), he underwent insertion of dual MCGRs (MAGEC ${ }^{R}$ MAGnetic Expansion Control system [MAGEC]; NuVasive) with pedicle screws at T2-4 proximally and L1-2 distally using standard fusion techniques with decortication and allograft. A chest tube catheter was used to guide placement of the rods intramuscularly in the subfascial plane. Standard $5.5-\mathrm{mm}$ MAGEC rods ${ }^{\mathrm{R}}$ (NuVasive) with a 90-mm actuator were applied to the concave side of the deformity, which allow elongation up to $48 \mathrm{~mm}$. A 70-mm actuator, allowing $28 \mathrm{~mm}$ of elongation, was placed on the convex side of the spine because the shorter actuator allowed better contouring to the extensive curvatures. The rods were tested before insertion and lengthened after insertion by $4 \mathrm{~mm}$ on the concavity and $2 \mathrm{~mm}$ on the convexity, which was confirmed by fluoroscopy before closure. Initial postoperative imaging showed residual Cobb angles of $57^{\circ}$ in the thoracic spine and $73^{\circ}$ of thoracic kyphosis (Fig. 2A and B).

Four months after MAGEC rod implantation, the patient underwent lengthening with a total of 14 distractions ranging from 1 to 3 $\mathrm{mm}$ at a time, approximately every 3.3 months, and resulting in total elongation of an average of 26 and $22.5 \mathrm{~mm}$ on the concave and convex sides, respectively. Radiographs taken before and after each distraction confirmed proper lengthening. However, over the course of 6 months, when he was 12 years old, it was noted that the patient's rods ceased lengthening and his curves were progressing. At that time, the patient had achieved substantial thoracic height $(T 1-12$ distance $22 \mathrm{~cm})$, had grown significantly $(147.3 \mathrm{~cm}$, $79.9 \mathrm{~kg}$, BMI $36.8 \mathrm{~kg} / \mathrm{m}^{2}, 100$ th percentile by weight, 85 th percentile by stature), and had reached a Sanders stage of 3 in skeletal maturity scoring. His spine deformity stabilized at $80^{\circ}$ of kyphosis and $55^{\circ}$ of scoliosis (Fig. $2 \mathrm{C}$ and D). Approximately 3 months later, the patient underwent removal of the MAGEC rods (NuVasive) and definitive posterior spinal instrumentation and fusion.

During the hardware removal procedure, it was noted that the patient had complete autofusion at $\mathrm{T} 1-4$, at the convexity between
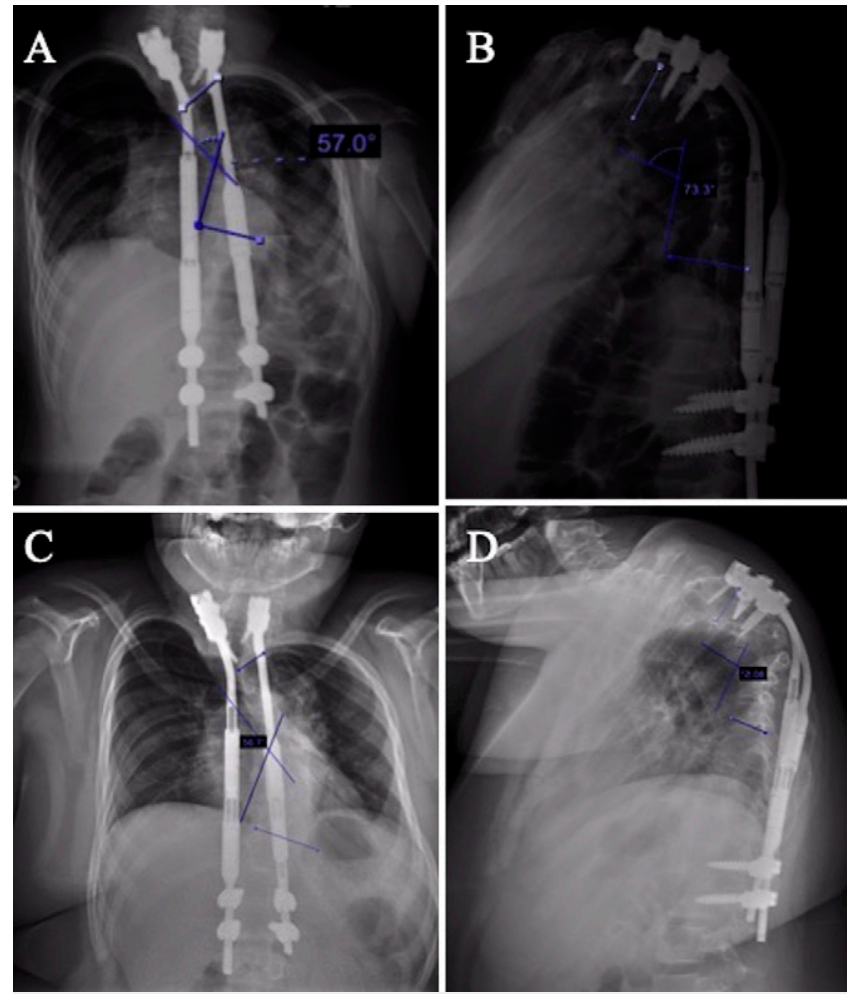

FIG. 2. After MAGEC rod insertion (A and B) and 4 years after insertion (C and D).

T8 and T10, and in the lumbar spine at L1-2 extending up to T12. There was also evidence of partial fusion of T6-7 and T7-8 (Fig. 3). Although initially placed subfascially, the MAGEC rods were in contact with the posterior elements of the spine. We also noted significant diffuse metallosis throughout the surrounding tissues but no signs of mechanical failure of the rods. The final procedure was performed successfully. The postoperative radiograph revealed residual $44^{\circ}$ scoliosis and $64^{\circ}$ kyphosis (Fig. 4A and B). At the last postoperative visit, 3 months after the last procedure, he presented without significant complaints. A radiograph confirmed spinal fusion with Cobb angles of $44^{\circ}$ and $66^{\circ}$ kyphosis (Fig. $4 C$ and D).

\section{Discussion}

\section{Observations}

MCGRs are gaining popularity as a surgical treatment option for the correction of moderate to severe early-onset scoliosis. The MAGEC ${ }^{R}$ rod system (NuVasive) is currently the only Food and Drug Administrationapproved MCGR in the United States and Europe. ${ }^{6}$ This technology allows the spine to continue to grow while controlling curve progression and limiting the number of subsequent surgeries.

Autofusion with TGRs has been identified before., ${ }^{2,7}$ Cahill et al.'s retrospective case review ${ }^{2}$ of nine skeletally immature patients treated with growing rods found a high rate of autofusion (89\%), with an average Cobb angle correction of $44 \%$. They attributed autofusion to immobilization, disruption of the surrounding soft tissues, and immense healing capacity of the immature spine. The average time between lengthening procedures was 10.4 months, and the average number of surgeries was 11.7 per patient. Magnetic growing rods should minimize the risk of 


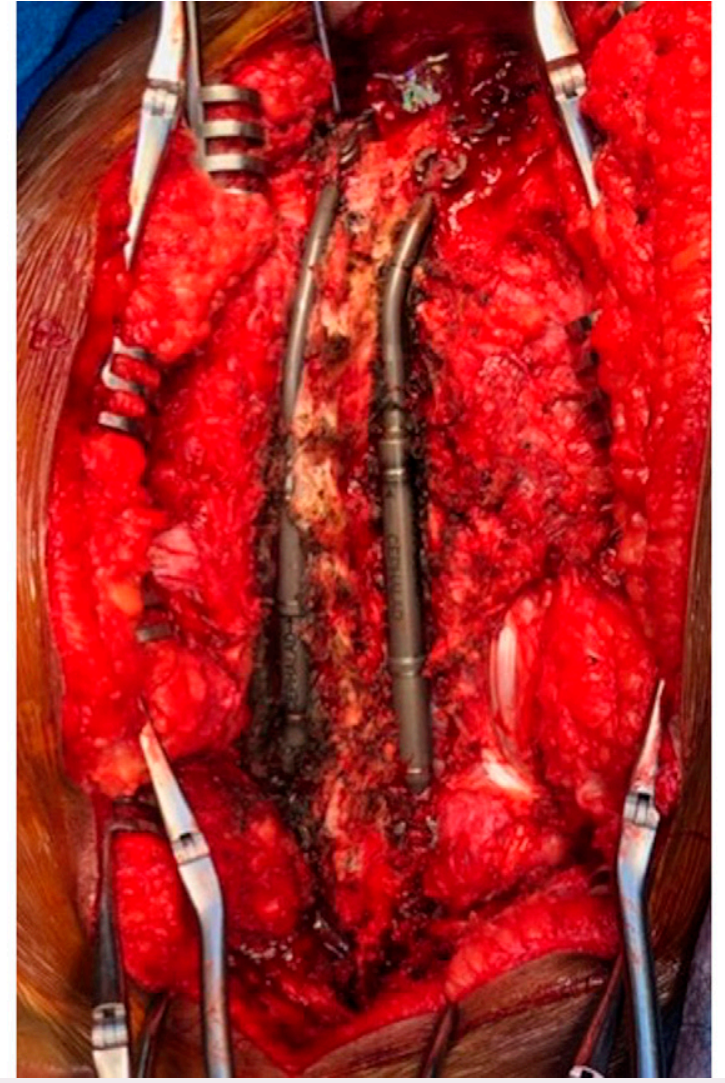

FIG. 3. Autofusion of T1-4, at the convexity between T8-10, and in the lumbar spine at L1-2 extending up to T12 noted during explant procedure.

autofusion due to more frequent lengthening and fewer operations that disrupt the paraspinal soft tissues.

Yoon et al., ${ }^{8}$ in their case series, demonstrated that the MCGR technique results in improvement in deformity correction, postoperative pulmonary function tests, and cost-effectiveness, as well as reductions in repeat anesthesia and surgical and psychological distress. In a cross-sectional study, Doany et al. ${ }^{9}$ compared the shortterm outcomes of early-onset scoliosis treatment with MCGR and TGRs. They concluded that patients undergoing MCGR have superior outcomes with higher overall satisfaction and lower financial burden compared with those who undergo TGR. Deformity correction and complication rates were similar in both groups. ${ }^{9}$ Although there is evidence suggesting that MCGRs have a reduced rate of postoperative infections compared with TGRs, the need for revision for other reasons, such as rod breakage, spinal fixation pullout, and progressive spinal stiffness, is not uncommon. 2,3,10

We report a case of a patient with early-onset scoliosis who underwent treatment with MCGRs and had evidence of premature fusion throughout the spine. It is unclear whether premature fusion occurred due to lack of rod elongation or vice versa. Gilday et al.., in their retrospective review analyzing the distraction achieved during MCGR lengthening, described the correlation between the magnitude of distraction and distance from the skin to the rod's actuator. The decrease in lengthening estimated by the authors was, on average, $2.1 \%$ per millimeter of tissue depth. ${ }^{11}$ Another interesting concept explaining the reduced gains during MCGR distractions
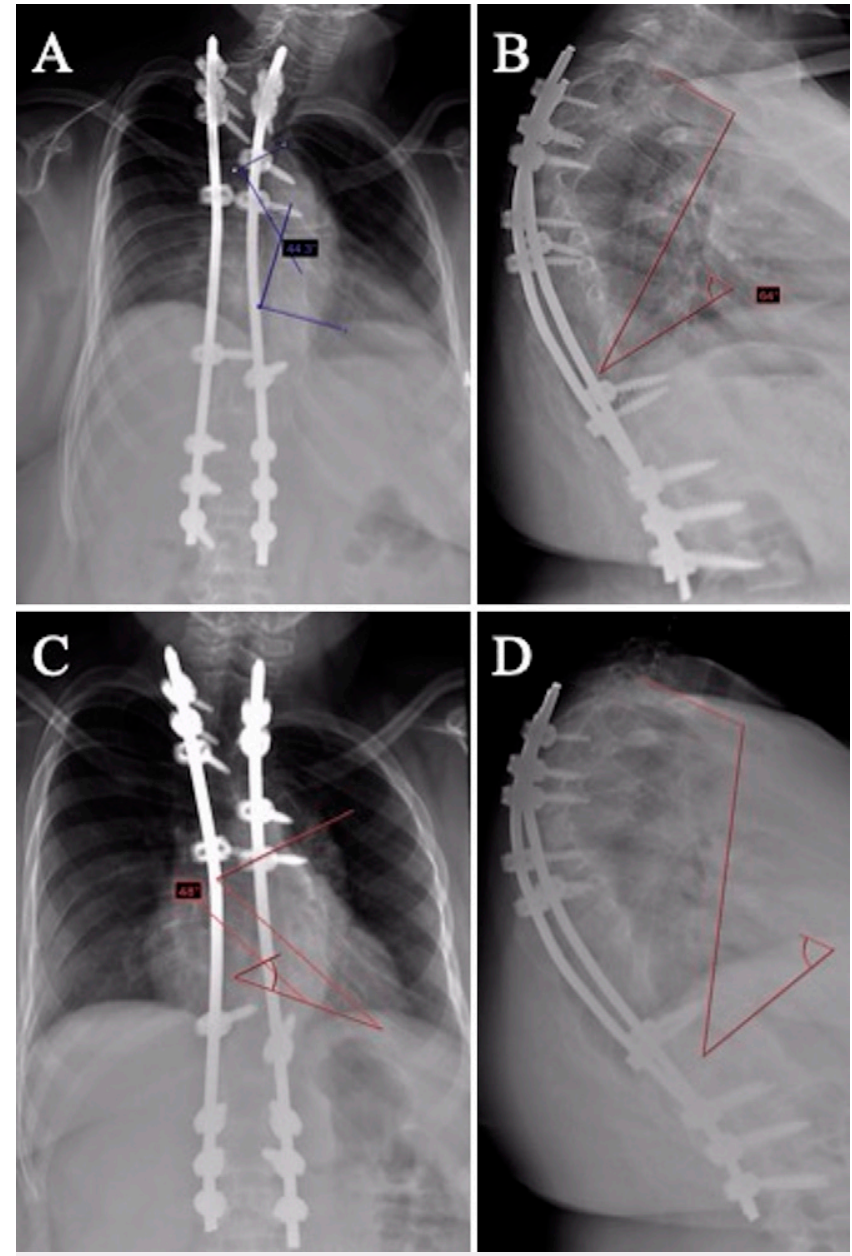

FIG. 4. After explant of MAGEC rods and definitive fusion (A and B) and 3 months later (C and $\mathbf{D})$.

over time was the concept of rod slippage presented by Cheung et al. ${ }^{12}$ The authors defined "slippage" as a failure of the internal magnet to complete a full revolution followed by stalling and a return to its initial position. $\mathrm{He}$ identified the increased distance from the external magnet to the actuator and the increased distance between internal magnets as risk factors for slippage occurrence. ${ }^{12,13}$ Our patient presented with a growth spurt preceding the time in which lengthening failure occurred. He gained $51 \mathrm{~kg}$, and his BMl increased to $36.8 \mathrm{~kg} / \mathrm{m}^{2}$ (100th percentile by weight, 85 th percentile by stature), and therefore distance from the controller to the actuator significantly increased, which might have contributed to the distraction failure.

Another hypothesis explaining decreased rod distraction with time is the "law of diminishing returns" proposed by Sankar et al. ${ }^{14}$ In that study, the authors evaluated the effectiveness of TGR lengthening over time. ${ }^{14}$ They concluded that the rate of distraction decreases with each subsequent lengthening and may be related to the progressive stiffness and autofusion of the spine subjected to the distraction. This is suggested to be due to paraspinal ligament microinjury and limited range of motion of the spine after rod implantation. The authors also postulated that the autofused spine can still gain length in response to distraction forces, but at a slower rate. This process can be explained by the high remodeling potential of newly formed bone after autofusion. ${ }^{14}$ Long-term studies have shown a similar concept of diminishing 
returns that is inherent to the rod rather than the patient. ${ }^{15}$ Cheung et al. ${ }^{15}$ illustrated increasing mismatch between the intended and observed lengthening of the rods with increasing lengthening, which is reset with rod exchange. In addition, Rushton et al. ${ }^{16}$ tested the force generated by the rods with correlation to the time from implantation. They demonstrated that the maximum force generated by the rod diminished with time, and, after 38 months, there was minimal or no potential to elongate. ${ }^{16}$ Although we saw early elongation and correction of the scoliosis from rod distraction in our case, there seemed to be diminishing returns after 43 months of distraction where the rod was reaching the end of its elongation potential.

We also observed metallosis surrounding the rods. There are reports that associate metallosis at the time of explant with hardware failure. ${ }^{5,17}$ Teoh et al. $^{18}$ postulated that metallosis is the result of the inflammatory response to the metal debris coming from microdamage of the rod's core or loss of seal by the internal 0 ring. In our case, we did not identify any macroscopic hardware failure. However, microscopic analysis was not performed, which is a limitation of our report. A striking observation in this case is the extent of fusion of the spine from T1 to L2, spanning the entire extent of the initial MAGEC rod construct, including segments that were not exposed during implantation. Because MCGRs have only recently been approved for use, we are still learning more about the longer-term effects and possible complications.

\section{Lessons}

We report a case of extensive premature spinal fusion after MCGR placement without evidence of macroscopic hardware failure. The greatest limitation is that the growing rods were not analyzed after explant. On the basis of our experience, important points to consider with MCGR procedures include (1) patient education regarding the high rate of complications, including elongation failure associated with the body habitus; (2) meticulous surgical technique with a focus on appropriate fixation technique and avoidance of periosteal stripping; and (3) maximum time of utility not exceeding 3 years due to increased risk of failure with time.

\section{Acknowledgments}

We thank Declan Tozzi, MD, for his contribution to this project.

\section{References}

1. Karol LA, Johnston C, Mladenov K, Schochet P, Walters P, Browne $\mathrm{RH}$. Pulmonary function following early thoracic fusion in non-neuromuscular scoliosis. J Bone Joint Surg Am. 2008;90(6):1272-1281.

2. Cahill PJ, Marvil S, Cuddihy L, et al. Autofusion in the immature spine treated with growing rods. Spine (Phila Pa 1976). 2010; 35(22):E1199-E1203.

3. Agarwal A, Kelkar A, Garg Agarwal A, Jayaswal D, Jayaswal A, Shendge V. Device-related complications associated with MAGEC rod usage for distraction-based correction of scoliosis. Spine Surg Relat Res. 2019;4(2):148-151.

4. Thakar C, Kieser DC, Mardare M, Haleem S, Fairbank J, Nnadi C. Systematic review of the complications associated with magnetically controlled growing rods for the treatment of early onset scoliosis. Eur Spine J. 2018;27(9):2062-2071.

5. Centers for Disease Control and Prevention, National Center for Health Statistics. Clinical growth charts. Accessed September 9, 2021. http://www.cdc.gov/growthcharts/clinical_charts. htm
6. Tsirikos Al, Roberts SB. Magnetic controlled growth rods in the treatment of scoliosis: safety, efficacy and patient selection. Med Devices (Auckl). 2020;13:75-85.

7. Fisk JR, Peterson HA, Laughlin R, Lutz R. Spontaneous fusion in scoliosis after instrumentation without arthrodesis. J Pediatr Orthop. 1995;15(2):182-186.

8. Yoon WW, Sedra F, Shah S, Wallis C, Muntoni F, Noordeen H. Improvement of pulmonary function in children with early-onset scoliosis using magnetic growth rods. Spine (Phila Pa 1976). 2014;39(15):1196-1202.

9. Doany ME, Olgun ZD, Kinikli GI, et al. Health-related quality of life in early-onset scoliosis patients treated surgically: EOSQ scores in traditional growing rod versus magnetically controlled growing rods. Spine (Phila Pa 1976). 2018;43(2):148-153.

10. Teoh $\mathrm{KH}$, Winson DM, James $\mathrm{SH}$, et al. Do magnetic growing rods have lower complication rates compared with conventional growing rods? Spine J. 2015;16(4 Suppl):S40-S44.

11. Gilday SE, Schwartz MS, Bylski-Austrow DI, et al. Observed length increases of magnetically controlled growing rods are lower than programmed. J Pediatr Orthop. 2018;38(3):e133-e137.

12. Cheung JPY, Yiu K, Samartzis D, Kwan K, Tan J, Cheung KMC. Paper \#27: Rod lengthening with the magnetically controlled growing rod: factors influencing rod slippage and reduced gains during distractions. Spine Deform. 2017;5(6):453.

13. Cheung JPY, Cahill P, Yaszay B, Akbarnia BA, Cheung KM. Special article: Update on the magnetically controlled growing rod: tips and pitfalls. J Orthop Surg (Hong Kong). 2015;23(3):383-390.

14. Sankar WN, Skaggs DL, Yazici M, et al. Lengthening of dual growing rods and the law of diminishing returns. Spine (Phila $\mathrm{Pa}$ 1976). 2011;36(10):806-809.

15. Cheung JPY, Bow C, Cheung KMC. "Law of temporary diminishing distraction gains": the phenomenon of temporary diminished distraction lengths with magnetically controlled growing rods that is reverted with rod exchange. Global Spine J. Published online August 17, 2020. doi: https://doi.org/10.1177/2192568220948475.In press.

16. Rushton PRP, Smith SL, Forbes L, Bowey AJ, Gibson MJ, Joyce TJ. Force testing of explanted magnetically controlled growing rods. Spine (Phila Pa 1976). 2019;44(4):233-239.

17. Joyce TJ, Smith SL, Rushton PRP, Bowey AJ, Gibson MJ. Analysis of explanted magnetically controlled growing rods from seven UK spinal centers. Spine (Phila Pa 1976). 2018;43(1):E16-E22.

18. Teoh $\mathrm{KH}$, von Ruhland $\mathrm{C}$, Evans SL, et al. Metallosis following implantation of magnetically controlled growing rods in the treatment of scoliosis: a case series. Bone Joint J. 2016;98-B(12): 1662-1667.

\section{Disclosures}

The authors report no conflict of interest concerning the materials or methods used in this study or the findings specified in this paper.

\section{Author Contributions}

Conception and design: Green, Brzezinski, Ishmael, Bowe. Acquisition of data: Green, Brzezinski, Ishmael, Bowe. Analysis and interpretation of data: Green, Brzezinski, Ishmael, Bowe. Drafting the article: Green, Brzezinski, Ishmael, Bowe. Critically revising the article: all authors. Reviewed submitted version of manuscript: Green, Ishmael, Bowe. Approved the final version of the manuscript on behalf of all authors: Green. Study supervision: Ishmael.

\section{Correspondence}

Anna H. Green: Robert Wood Johnson University Hospital, New Brunswick, NJ. annagreen7@gmail.com. 